This document was prepared in conjunction with work accomplished under Contract No. DE-AC09-96SR18500 with the U.S. Department of Energy.

This work was prepared under an agreement with and funded by the U.S. Government. Neither the U. S. Government or its employees, nor any of its contractors, subcontractors or their employees, makes any express or implied: 1 . warranty or assumes any legal liability for the accuracy, completeness, or for the use or results of such use of any information, product, or process disclosed; or 2 . representation that such use or results of such use would not infringe privately owned rights; or 3 . endorsement or recommendation of any specifically identified commercial product, process, or service. Any views and opinions of authors expressed in this work do not necessarily state or reflect those of the United States Government, or its contractors, or subcontractors. 
Proceedings of PVP2007-26294

2007 ASME Pressure Vessels and Piping Division Conference July 22-26, 2007, San Antonio, Texas

PVP2007-26294

\title{
DYNAMIC ANALYSIS OF THE BULK TRITIUM SHIPPING PACKAGE SUBJECTED TO CLOSURE TORQUES AND SEQUENTIAL IMPACTS
}

\author{
Tsu-te Wu \\ Paul S. Blanton \\ Kurt R. Eberl \\ Savannah River National Laboratory \\ Aiken, South Carolina 29803 \\ (803) 725-8201, tsu-te.wu@srnl.doe.gov
}

\begin{abstract}
This paper presents a finite-element technique to simulate the structural responses and to evaluate the cumulative damage of a radioactive material packaging requiring bolt closure-tightening torque and subjected to the scenarios of the Hypothetical Accident Conditions (HAC) defined in the Code of Federal Regulations Title 10 part 71 (10CFR71). Existing finite-element methods for modeling closure stresses from bolt pre-load are not readily adaptable to dynamic analyses. The HAC events are required to occur sequentially per 10CFR71 and thus the evaluation of the cumulative damage is desirable. Generally, each HAC event is analyzed separately and the cumulative damage is partially addressed by superposition. This results in relying on additional physical testing to comply with 10CFR71 requirements for assessment of cumulative damage. The proposed technique utilizes the combination of kinematic constraints, rigid-body motions and structural deformations to overcome some of the difficulties encountered in modeling the effect of cumulative damage. This methodology provides improved numerical solutions in compliance with the 10CFR71 requirements for sequential HAC tests.
\end{abstract}

Analyses were performed for the Bulk Tritium Shipping Package (BTSP) designed by Savannah River National Laboratory to demonstrate the applications of the technique. The methodology proposed simulates the closure bolt torque preload followed by the sequential HAC events, the 30-foot drop and the 30-foot dynamic crush. The analytical results will be compared to the package test data.

\section{INTRODUCTION}

Packages designed for the shipment of radioactive materials are required to comply with the acceptance criteria for the Hypothetical Accident Conditions defined in 10 CFR 71. The HAC events occur sequentially as follows.

1. The package falls 30 feet from the bridge to impact an essentially rigid road surface below.

2. The package is impacted by a 1100 -pound wreckage fragment (a steel plate) falling 30 feet from above.

3. The package bounces into the air and upon descent falls 40 inches to impact a broken axle stub.

Prior to the dynamic loading described above, the containment vessel is subjected to the torque load as the closure bolt is tightened to the flange. The containment vessel contains residual stresses after the torque load is removed.

This paper presents a numerical technique to predict the cumulative damage of the closure load followed by the sequential HAC dynamic loads. The technique is applied to two analytical cases for the Savannah River National Laboratory designed Bulk Tritium Shipping Package (BTSP). The analytical cases are differentiated by the drum orientation during the 30 -foot drop and crush simulations. 
The analyses do not include the 40-inch impacts since past experience indicates they generally do not result in significant structural damage.

The development of the Bulk Tritium Shipping Package is an on-going program and thus the analytical results will be verified with experimental data at a later date.

\section{ANALYSIS}

The analysis is performed using the finite-element method and the ABAQUS/Explicit computer code, version 6.6 [1].

The finite-element model is developed using the MSD/PATRAN computer program [2].

\section{Finite-Element Model}

Figure 1 shows the cut-away illustration of Bulk Tritium Shipping Package which was analyzed. Since the geometrical configuration and the loading conditions are symmetric with respect to a certain plane passing through the axis of the package, the finite-element model need only include one half of the package.

The finite-element model of the Containment Vessel (CV) is comprised of 3D solid elements (Type C3D8R). The drum overpack is modeled using both $3 \mathrm{D}$ solid elements (Type C3D8R and C3D6) and 3D shell elements (Type S4R). The 1100-pound falling wreckage and the unyielding floor are modeled with rigid elements (Type R3D4).

The analyses simulate the HAC sequential tests of a 30 foot drop and a 30-foot crush. The bolt pre-load in the containment vessel from the closure tightening is also simulated, but not the torque loading. The following two cases with different drop orientations are analyzed.

Case 1: The 30-foot free fall onto the rigid floor occurs with the package in a horizontal orientation. The 1100pound rigid plate then falls from 30 -foot height and strikes the top side of the floor lying package (Figure 2).

Case 2: The 30-foot free fall onto the rigid surface occurs with the package upside down and tilted to align the package center of gravity over the corner (CGOC). The 1100 -pound rigid plate then falls from 30 -foot height and strikes the uppermost corner of the package when the package is in upside position (Figure 3).

\section{Analysis for Containment Closure Tightening}

The BTSP containment vessel has a total of 16 closure bolts, each of which is tightened by a torque to achieve a preload of -5000 pounds. The preload generated by closure tightening is critical to sealing performance of the containment vessel.
The closure preload is commonly modeled by an equivalent thermal load resulting from a temperature reduction in the bolt from the ambient temperature. Since the stresses involve three dimensional volume changes, it is difficult to determine the equivalent thermal load with good accuracy. Alternatively, a method of modeling the bolt by introducing a pre-tension is available in the ABAQUS finite-element computer code. However, the pre-tension method in ABAQUS is only applicable to the implicit numerical integration and therefore does not readily lend its use to the more practical explicit method for the complex dynamic problems discussed herein.

A quasi-static numerical technique for simulating the torque preload was proposed in previous analyses [3]. This paper presents an improved version of the similar technique.

As shown in Figure 4, the external and internal threads of the bolt and the flange, respectively, are arbitrarily represented by two thin cylindrical shells 0.0005 inches thick. These cylindrical shells, defined as 3D rigid shell elements, are superimposed on the bolt and flange. Since the individual threads deform simultaneously, the use of rigid shell elements is appropriate. A 3D Connector Element (ABAQUS Element Type CONN3D2) is defined with a reference node on each cylindrical shell. The connector element will provide a connection between the bolt and flange threads.

To avoid inadvertently merging the nodes on the interfaces between the lid and the flange and between the bolt head and the lid, an arbitrary clearance of 0.1 inches is introduced between the lid-flange interfaces as well as the bolt-lid interfaces.

The process of simulating the bolt tightening is performed in two load steps. The first load step is to close the interface gaps by specifying the rigid-body motions to the bolt and the lid. In the second load step, a negative force of 5000 pounds is applied to Node 2 in the bolt (see Figure 4) of the connector element. The value of the force in each bolt varies smoothly from zero to -5000 pounds during the duration of 0.005 seconds. Since the rate of the applied bolt force is zero when it reaches -5000 pounds, the force resulting from the simulated torque remains constant before the subsequent HAC loadings occurs. The relative locations of the Connector Element nodes are fixed through the utilization of the ABAQUS locking option.

\section{Dynamic Analysis of 30-Foot Drop}

The analytical simulation of a 30-foot drop event consists of two additional load steps. The first load step establishes the initial velocity, or velocity on impact, at the end of the 30 -foot drop of the package. The second load step simulates the 30 -foot wreckage drop onto the package. 
This technique applies to both analysis cases.

Determination of Velocity at Impact: Conventionally, the velocity of the package at the end of the 30-foot drop will be used as the initial velocity in the drop analysis. Since the torque load is applied prior to the 30 -foot drop the initial velocity of the 30 -foot drop can not be specified at time zero. As a result, the following technique is used to establish the velocity upon impact of the package with the surface.

A velocity-type boundary condition is applied to the package with a smooth velocity profile that varies from zero to the maximum free-fall velocity, $V_{0}$.

$$
V_{o}=\sqrt{2 \times 386.4 \frac{i n}{\mathrm{sec}^{2}} \times 30 f t \times 12 \times \frac{i n}{f t}}=527.454 \frac{\mathrm{in}}{\mathrm{sec}}
$$

The velocity profile is applied over a time period, $1.5 t_{0}$, where $t_{0}$ is determined from the following equation. An assumed small distance, $d$, represents the initial location where the package is located above the surface in the model.

$$
t_{0} \times 0.5 V_{0}+\left(1.5 t_{0}-t_{0}\right) \times V_{0}=d
$$

Figure 5 shows the package velocity is assumed to increase from zero to $527.454 \mathrm{in} / \mathrm{sec}$ during the time period of from zero to $t_{0}$ and then remains constant during the time period from $t_{0}$ to $1.5 t_{0}$. Since the velocity is a smooth function and it remains constant from the time equal to $t_{0}$ until impact occurs, the assumed rigid body motion of the package over the distance, d, will not generate any undesirable acceleration.

For these analyses, $\mathrm{d}$ is assumed to be 0.07 inches and calculated value of the duration, $\mathrm{t}_{0}$, is $1.327 \mathrm{E}-4$ seconds.

Impact Analysis: The second load step simulates the 30 foot package drop onto the simulated rigid surface. The package is subjected to the gravitational load and the reference node for the impacted rigid surface is fixed in space.

\section{Dynamic Analysis of 30-Foot Crush}

The analytical simulation of a 30 -foot crush event consists of two additional load steps. The first step establishes the 30 -foot free-fall velocity of the 1100-pound steel plate. The second load step simulates the impact of the plate with the package.

\section{DISCUSSION OF ANALYTICAL RESULTS}

\section{Analysis for Containment Closure Tightening}

Figure 6 and Figure 7 show the stress distributions in the $\mathrm{CV}$ bolts and flange and the stress distribution the CV lid, respectively, caused by the bolt torque preload. The resulting stresses are within the elastic limit [4].

\section{Case 1 Analysis of 30-Foot Lateral Drop and 30-Foot} Lateral Crush

Energy History: Figure 8 shows the energy time-history plots for the 30 -foot drop followed by 30 -foot crush for Case 1 analysis.

Deformed Shapes: Figures 9 and 10 depict the deformed shapes for the package and the 30-foot lateral drop and 30foot lateral crush, respectively.

Stress Distributions: Figure 11 shows the stress distribution in the $\mathrm{CV}$ after the sequential drop and crush analyses. The maximum von Mises stresses are within the allowable limits [4].

Strain Distributions: Figure 12 displays the strain distribution in the drum overpack after the sequential drop and crush analyses.

\section{Case 2 Analysis of 30-Foot CGOC Drop and 30-Foot CGOC Crush}

Energy History: Figure 13 shows the energy time-history plots for the 30-foot CGOC drop followed by a 30-foot CGOC crush for Case 2 analyses, respectively.

Deformed Shapes: Figures 14 and 15 depict the deformed shapes of the package after the 30-foot CGOC drop and the 30-foot CGOC crush, respectively.

Stress Distributions: Figure 16 shows the stress distribution in the top part of the $\mathrm{CV}$ after the sequential drop and crush analyses. The maximum von Mises are within the allowable limits [4].

Strain Distributions: Figure 17 displays the strain distribution in the drum overpack after the sequential drop and crush analyses. The maximum effective plastic strain of 0.47 occurs locally in the bottom drum band after a 30foot crush. 


\section{CONCLUSIONS}

Nonlinear analyses were performed for the Bulk Tritium Shipping Package subjected to the closure preloads and the sequential HAC impacts. A new numerical technique to simulate the closure bolt preload has been defined.

The analytical results indicate that the structural integrity of the BTSP is maintained when subjected to the HAC events. The results also show that the closure of the containment vessel remains tightened after the HAC events.

It is more accurate and convenient to evaluate structural damages in HAC events based on cumulative plastic deformations than on the current stress criteria defined in the ASME Code [4]. The analytical method presented in this paper allows more accurate modeling of the cumulative damage from sequential events, thereby providing a gateway to transitioning from the current stress criteria to strain-based acceptance criteria.

\section{REFERENCES}

1. ABAQUS, Inc., ABAQUS/Explicit User's Manual, Version 6.6.

2. MSC/PATRAN, Version 2003r2, MacNealSchwendler Corp., 2003.

3. Wu, T. T. A Technique for Dynamic Analyses of Containers with Locking-Ring Closures, Transportation, Storage, and Disposal of Radioactive Materials, PVP-Vol. 449.

4. ASME B\&PVC, Section III, Division 1, Nonmandatory Appendix F, Article F-1000, Rules for Evaluation of Service Loadings with Level D Service Limits, 2004.

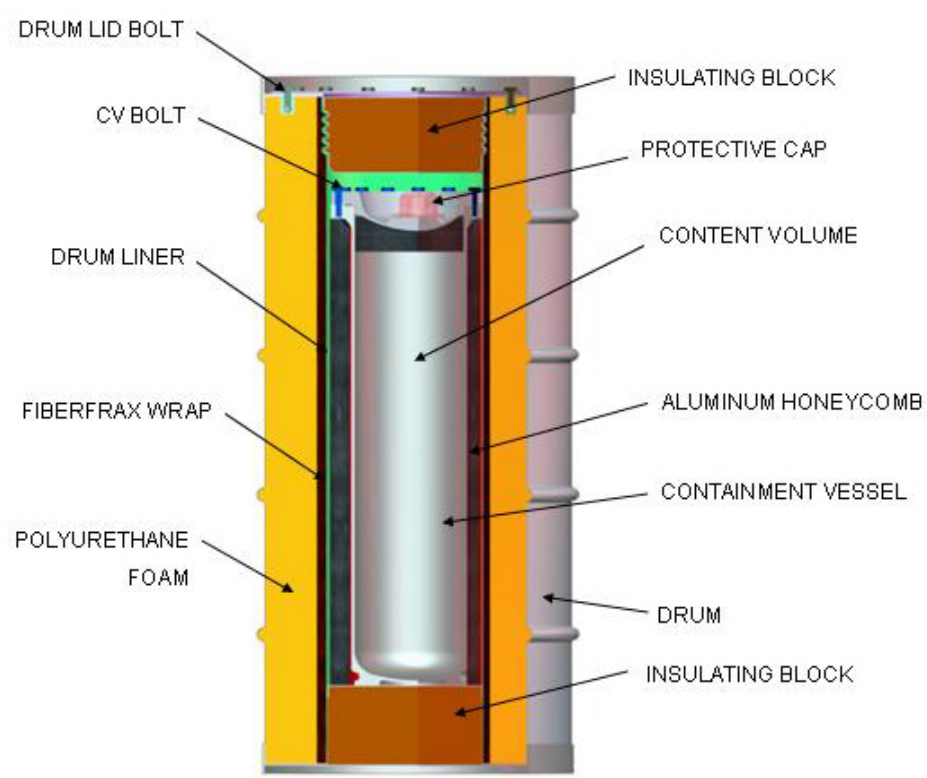

Figure 1. Bulk Tritium Shipping Package

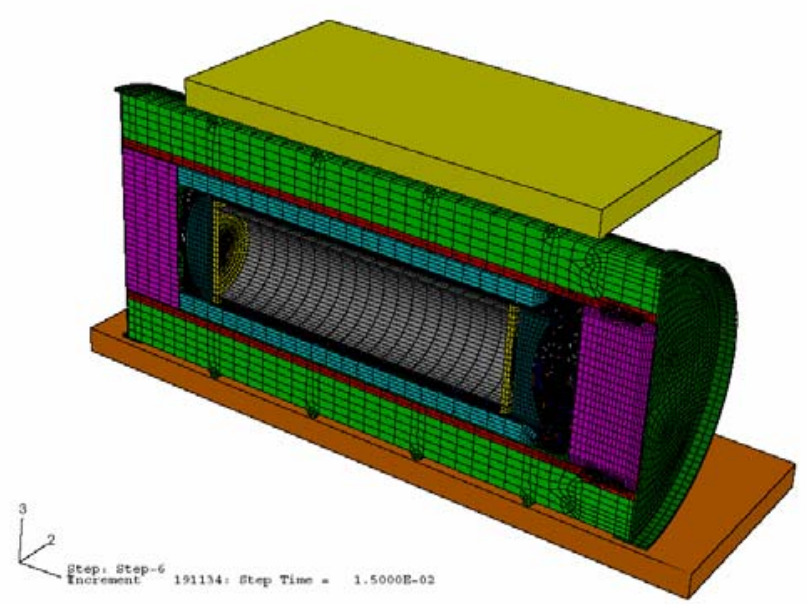

Figure 2. Finite-Element Model for 30-Foot Lateral Drop and 30-Foot Lateral Crush Analysis - Case 1 


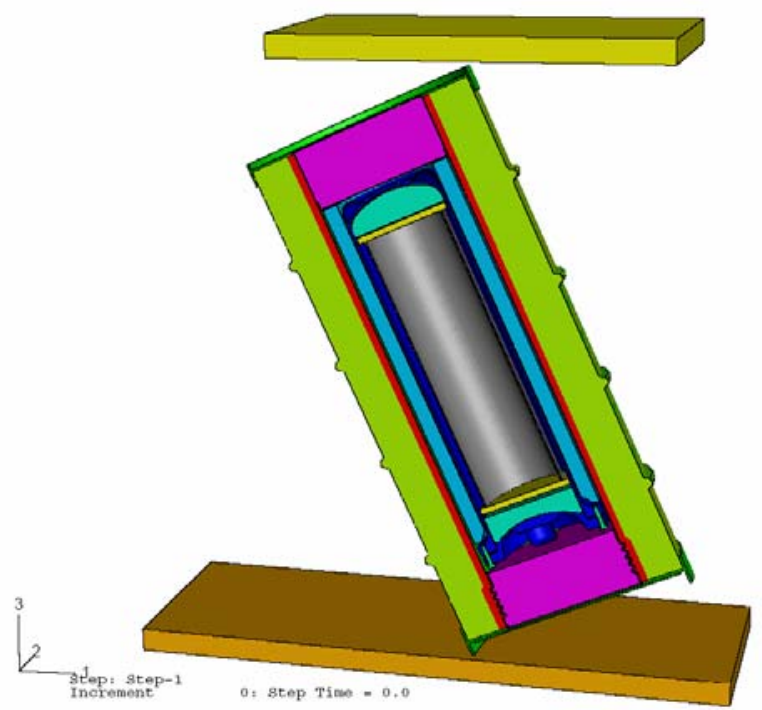

Figure 3. Finite-Element Model for 30-Foot CGOC Drop and 30-Foot CGOC Crush - Case 2

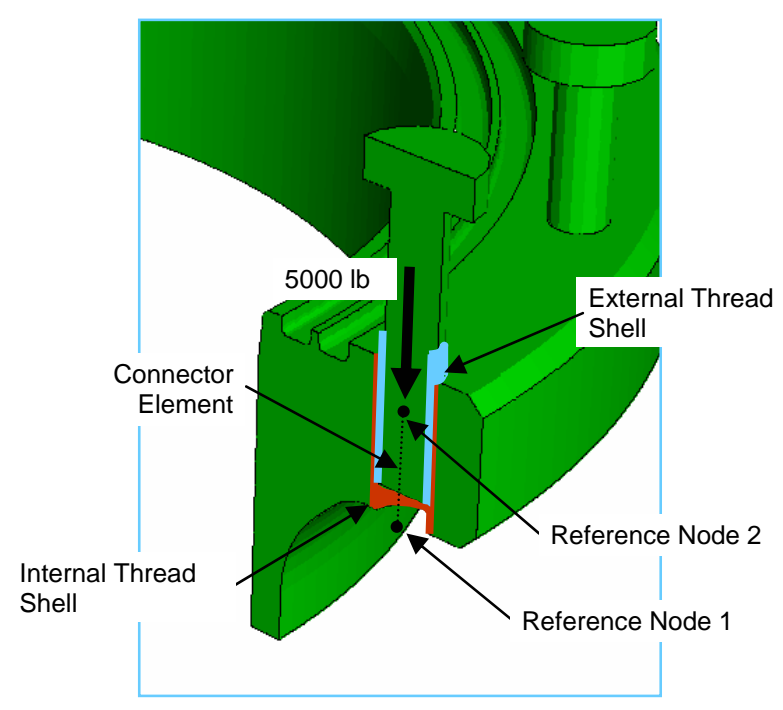

Figure 4. Illustration of Torque Load Model

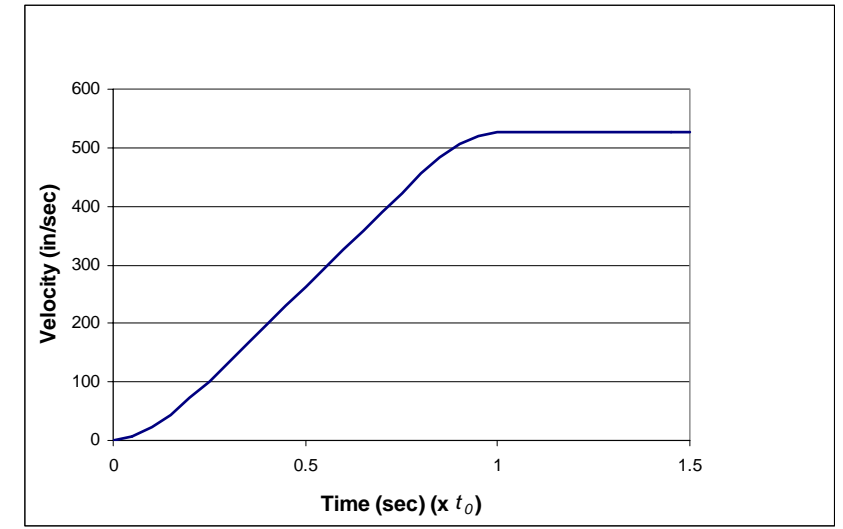

Figure 5. 30-Foot Drop Velocity Profile

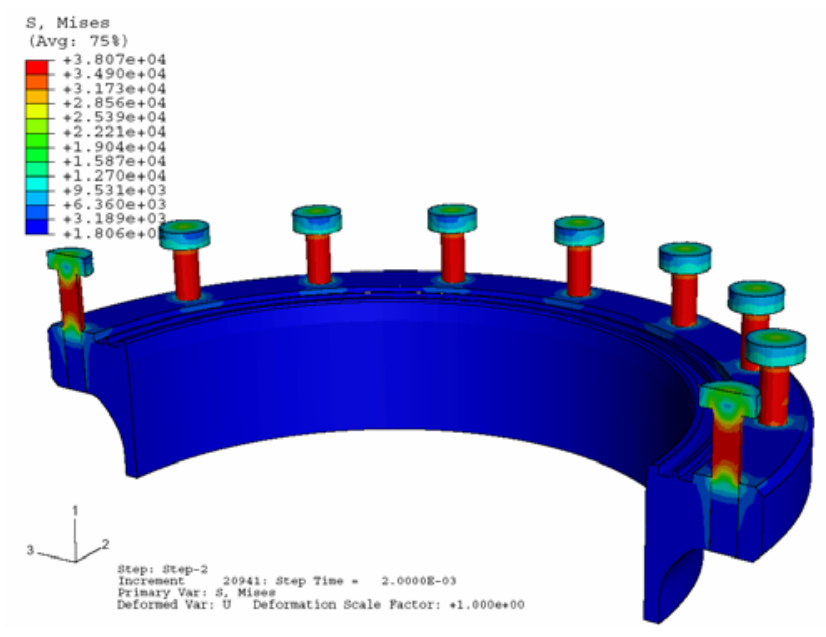

Figure 6. Stress in the CV Bolts Caused by Closure Torque 


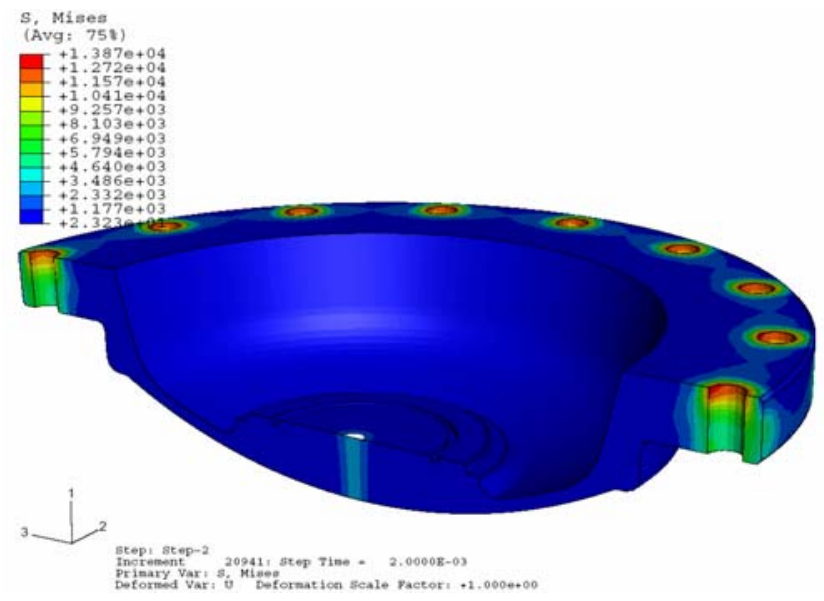

Figure 7. Stress in the CV Lid Caused by Closure Torque

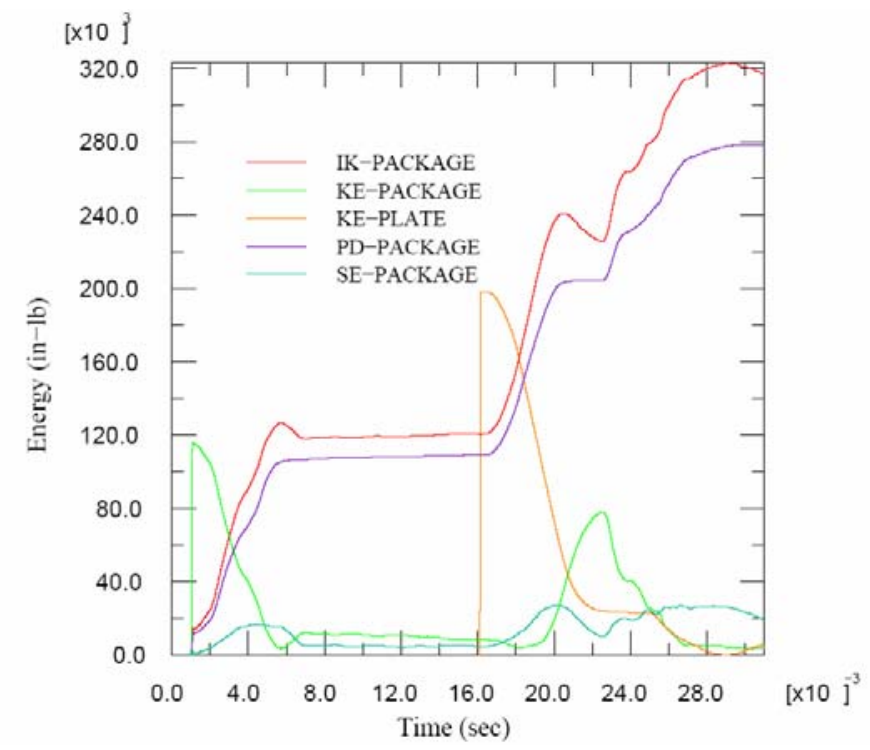

(IK-PACKAGE, KE-PACKAGE, PD-PACKAGE, and SE-PACKAGE = Internal, kinetic, Plastic dissipation and Elastic Strain Energies of Package; KE-PLATE = Kinetic Energy of Steel Plate)

Figure 8. Energy Variation for Case 1 Analysis - 30-Foot Lateral Drop and 30-Foot Lateral Crush

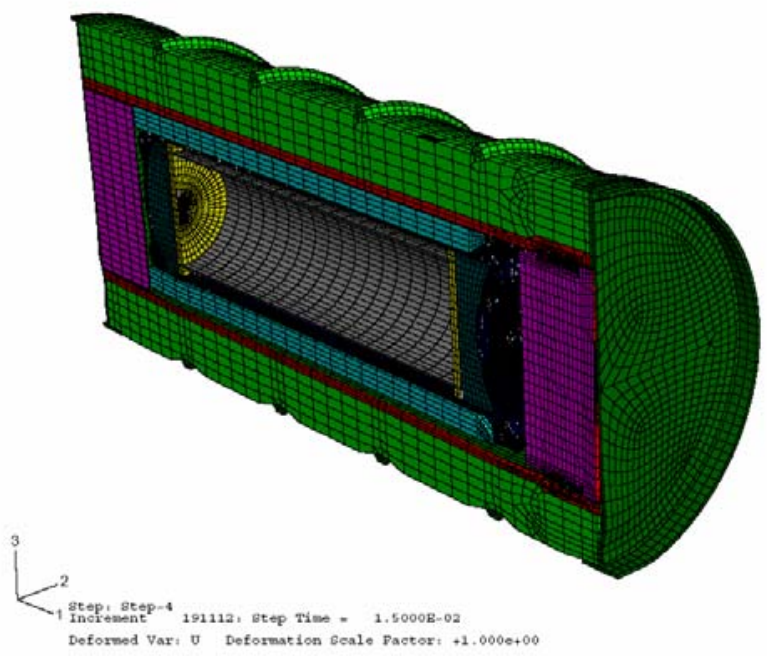

Figure 9. Deformed Shape after a 30-Foot Lateral Drop -- Case 1 Analysis

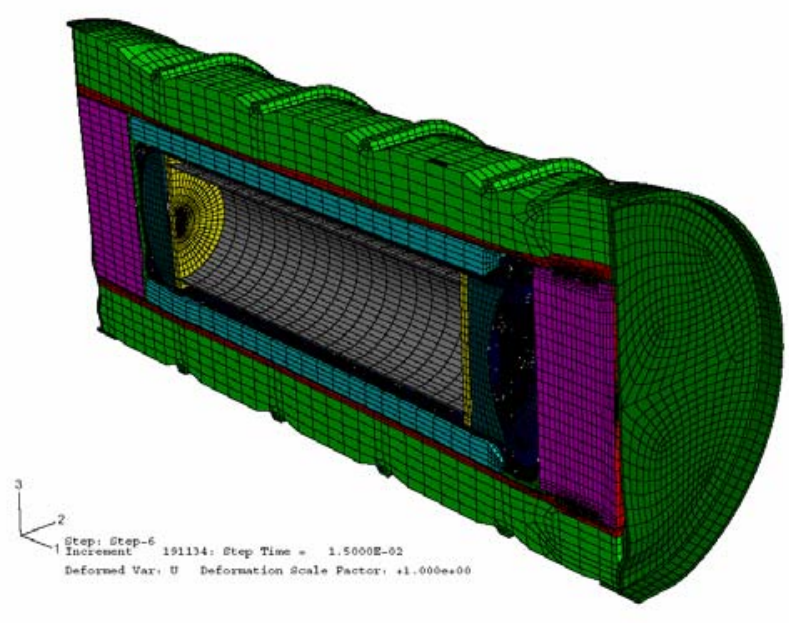

Figure 10. Deformed Shape after a 30-Foot Lateral Crush -- Case 1 Analysis 


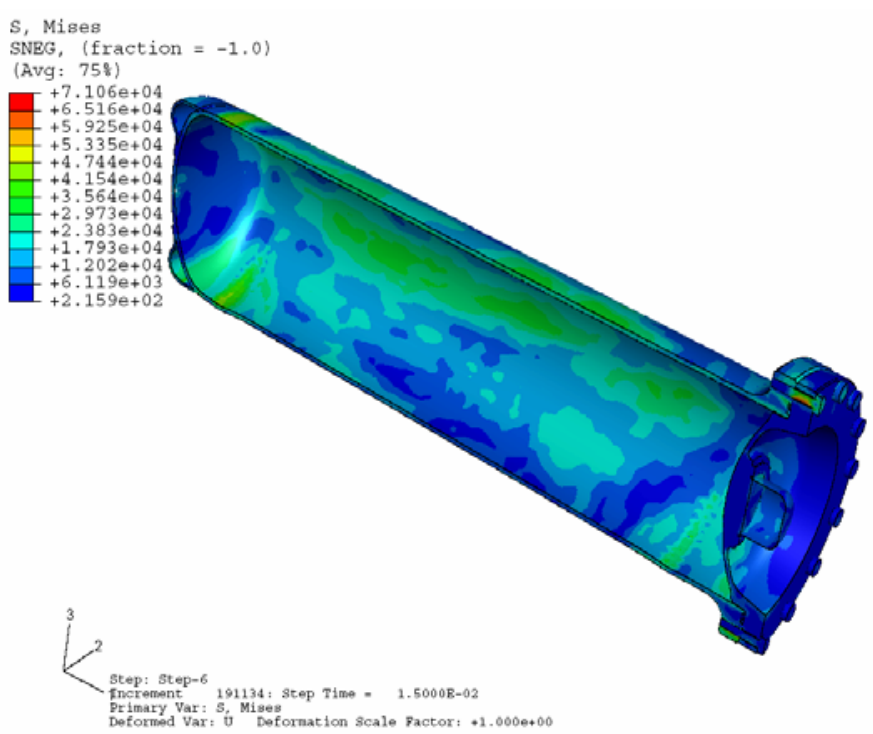

Figure 11. Stress Distribution in CV after a 30-Foot Lateral Drop followed by a 30-Foot Lateral Crush -- Case 1 Analysis

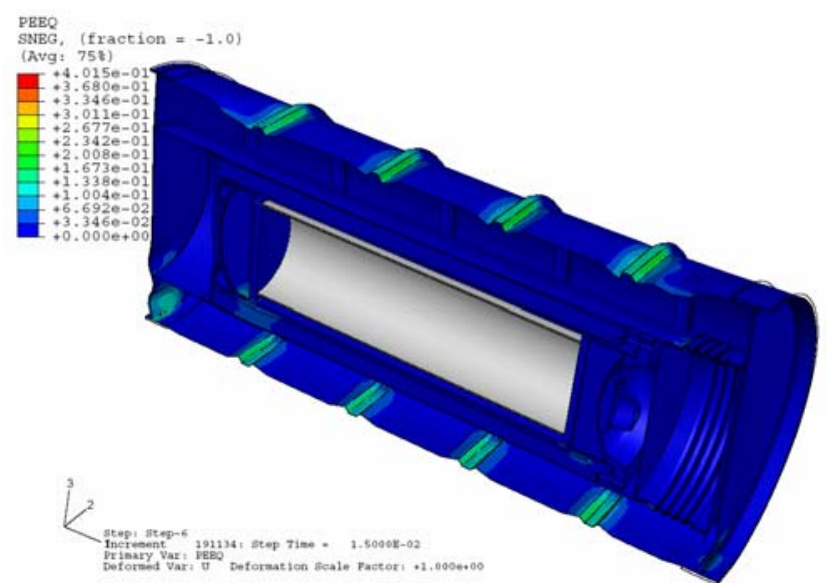

Figure 12. Strain Distribution in Metal Components of Overpack after a 30-Foot Lateral Drop followed by a 30-Foot Lateral Crush - Case 1 Analysis

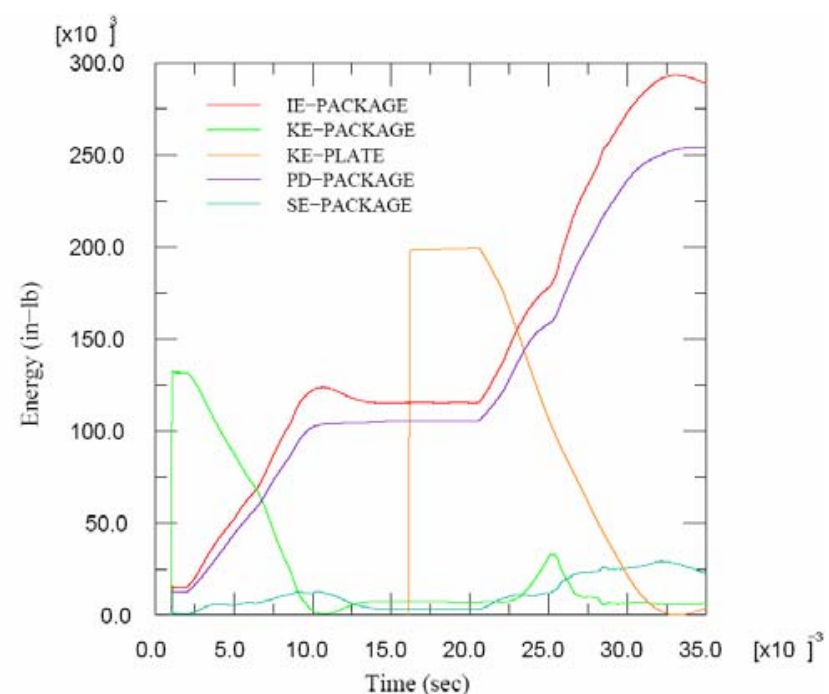

(IK-PACKAGE, KE-PACKAGE, PD-PACKAGE, and SE-PACKAGE = Internal, kinetic, Plastic dissipation and Elastic Strain Energies of Package; KE-PLATE = Kinetic Energy of Steel Plate)

Figure 13. Energy Variation for a 30-Foot CGOC Drop followed by a 30-Foot CGOC Crush

-- Case 2 Analysis

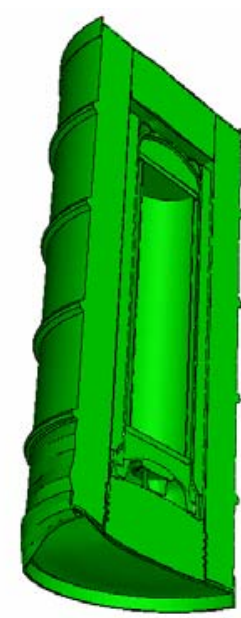

Figure 14. Deformed Shape after a 30-Foot CGOC Drop -- Case 2 analysis 


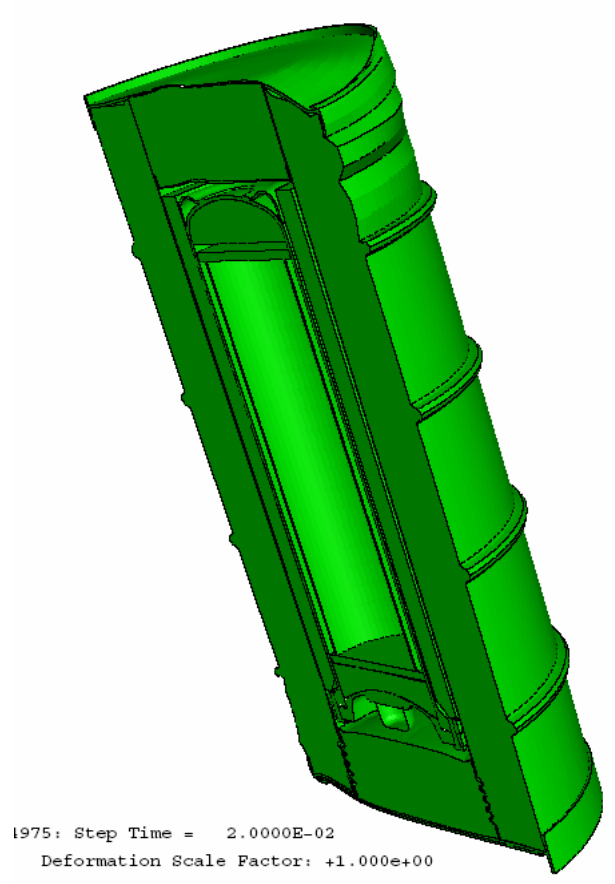

Figure 15. Deformed Shape after a 30-Foot CGOC Crush -- Case 2 Analysis

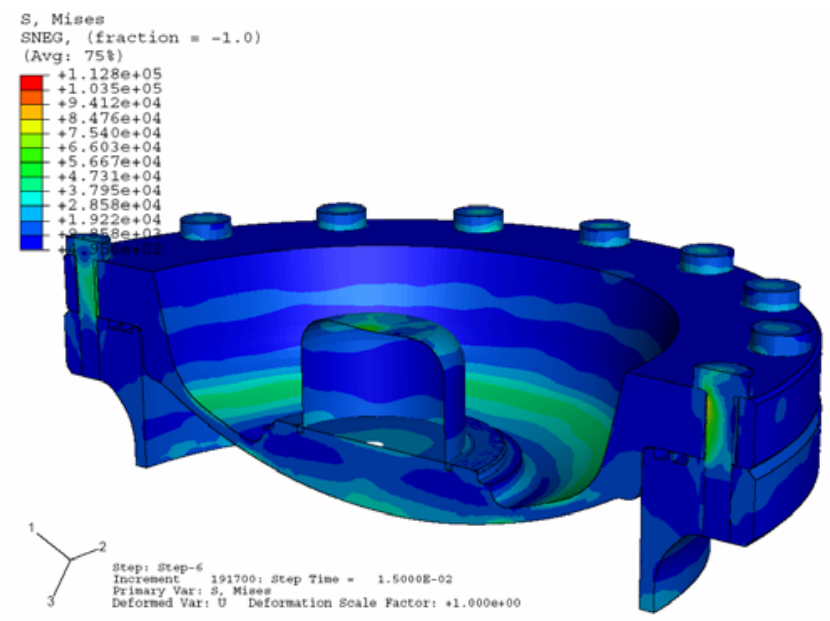

Figure 16. Stress Distribution in CV after a 30-Foot CGOC Drop followed by a 30-Foot CGOC Crush -- Case 2 Analysis

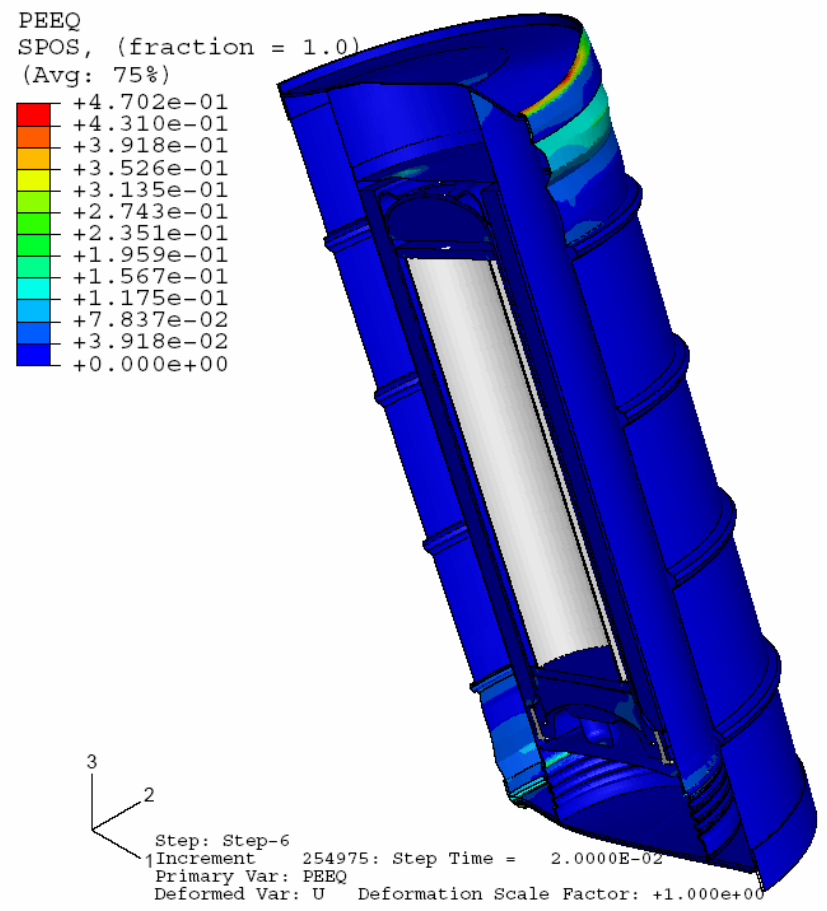

Figure 17. Strain Distribution in Metal Components of Overpack after a 30-Foot Crush -- Case 2 Analysis 